\title{
A PRELIMINARY NOTE ON THE ELECTRICAL RESPONSE TO SHADOWS OF THE ANTHOMEDUSA, SPIROCODON SALTATRIX
}

\section{$\operatorname{AUTHOR}(\mathrm{S})$ :}

Yoshida, Masao; Ohtsu, Kohzoh

\section{CITATION:}

Yoshida, Masao ....[et al]. A PRELIMINARY NOTE ON THE ELECTRICAL RESPONSE TO SHADOWS OF THE ANTHOMEDUSA, SPIROCODON SALTATRIX. PUBLICATIONS OF THE SETO MARINE BIOLOGICAL LABORATORY 1973, 20: 647-651

\section{ISSUE DATE:}

1973-12-19

URL:

http://hdl.handle.net/2433/175753

RIGHT: 


\title{
A PRELIMINARY NOTE ON THE ELECTRICAL RESPONSE TO SHADOWS OF THE ANTHOMEDUSA, SPIROCODON SALTATRIX
}

\author{
MASAO YOSHIDA and KoHzoH OHTSU
}

Tamano Marine Laboratory, 2-3-3, Shibukawa, Tamano, Okayama, 706 Japan

With 1 Text-figure

Electrophysiological studies on hydrozoa have recently advanced considerably and various types of pulse have been noted in different animals, at different sites and in response to different stimuli. Some of them have been correlated to swimming (Mackie \& Passano, 1968), contraction (Passano \& McCullough, 1962), feeding (Passano \& McCullough, 1964) or luminescent (Morin \& Cooke, 1971) activities, but apart from the work on the dermal light sense of hydra (PASSANo \& MCCullough, 1964), no electrical correlate to photic reactions has been reported.

Photoreceptors of coelenterates show important structural characteristics in that they belong to the ciliary type of the EAKIN's totempole (1965). Indeed we have confirmed in Spirocodon saltatrix (anthomedusa) and Aurelia aurita (Scyphomedusa) that peripheral microvilli are outgrowth of the ciliary shaft, but what appears to be more important is that each cilium consists of 9 doublets with 2 central tubules (YAMASU \& Yoshida, 1973). Such a feature is consistent with the characteristics of the motile cilia but differs from those of the sensory cilia of higher animals which lack the 2 central tubules. Though recent work of light-sensitive unmodified cilia of bryozoan larvae (WoOllacotT \& ZrMmER, 1972) has made EAKIN (1972) to suggest "the possibility that relatively little structural modification may be necessary to endow a kinocilium with light sensitivity" (p. 636), the change over from motile to non-motile cilia may be considered to be an important step in evolution of photosensory cells. In this sense, we think that photoreceptors in cnidaria are worth studying from photophysiological view point.

Spirocodon saltatrix used in the present study responds to shadows by pulsation of the bell (KIKUCHI, 1947) and contraction of the tentacles (HISADA, 1956) and such responses are mediated through the ocelli (HisAdA, 1956). Further, medusae of the present species are uniquely suitable for physiological work on events occurring between the periphery and the center, for the nerve ring and the ocelli are separated by a long intervening distance. The distance sometimes reaches $8 \mathrm{~mm}$ but is usually $3-5 \mathrm{~mm}$ long. This happens so because during the course of development whereby the tentacles are increased in number, new tentacles are formed on either side of and slightly below 
old ones already formed, resulting in that the bases of old tentacles with the ocelli on their abaxial surfaces are connected with the marginal ring structures over the exumbrellar surface by tissues which are homologous with the tentacles. We will call this part the "subtentacular region". We will report below preliminarily electrical activities in the marginal ring structures and the subtentacular region in response to changes in light conditions.

Methods: Experiments were performed with a piece of bell margin which bore a part of the marginal ring structures (nerve ring, ring canal and sphincter muscle), the velum and several ocelli as shown in the figure on the right (note that the tentacles were cut short). The preparation was placed on a silver plate of the indifferent electrode. The recording electrode, an electrolytically polished insect pin, was lowered vertically onto the preparation by means of a micromanipulator. Electrical activities were amplified by condensor-coupled amplifiers (Nihon Kohden, AVB-2, AVH-2) and displayed on a dual beam cathod ray oscilloscope (Nihon Kohden, VC-7A). Light for stimulation was obtained from a tungsten filament lamp $(6 \mathrm{~V}, 30 \mathrm{~W})$ and was shone onto the preparation by means of a mirror system. The time of "on" or "off" of the light was controlled by a camera shutter and was signaled using the flash junction of it.

A

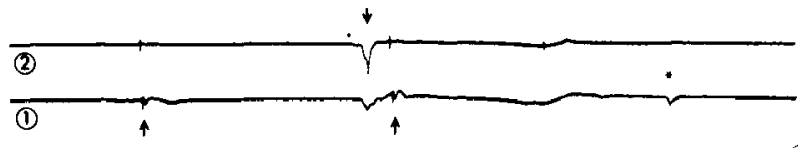

B

(2)
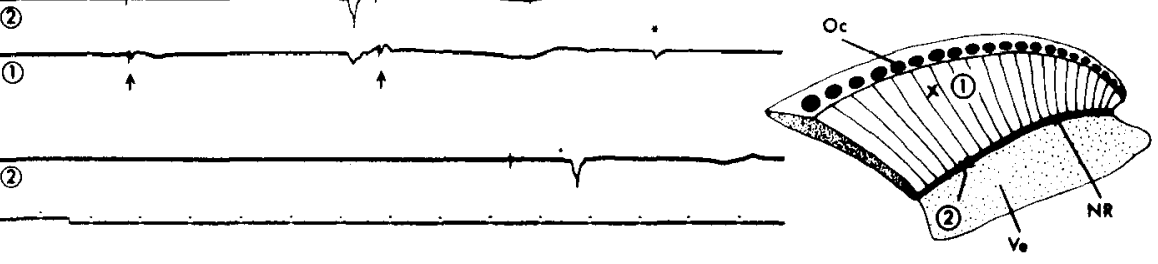

C

(3)

D

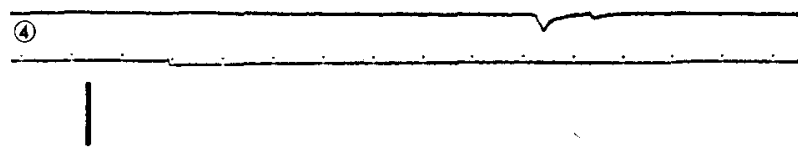

E
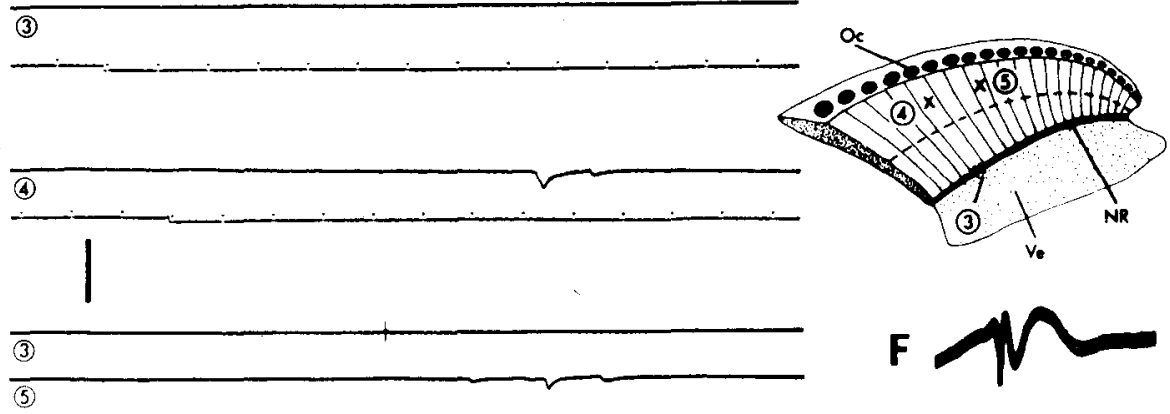

Fig. 1. Recordings obtained after light-off (A-D) at various positions (shown by numerals in the drawings). Pulses in $\mathbf{E}$ are spontaneous. Time mark in the lower records of B-D, $100 \mathrm{msec}$; $A$ and $E$, swept at the same rate as B-D. Vertical bar, $5 \mathrm{mV}$ in B, C and upper records of $A$ and $E ; 1 \mathrm{mV}$ in $\mathrm{D}$ and lower records of $\mathrm{A}$ and $\mathrm{E}$. F, six times magnification of the pulse marked by the second arrow in lower record of A. Oc: ocellus, NR: nerve ring, Ve: velum. 
Results and Discussion: Slow potentials of a kind found in other simple photoreceptors such as planaria (BRown \& OGden, 1968), Asterias (HARTLine et al., 1952) and a few others have never been recorded around the ocellar region. Electrical activities in response to a change in light conditions appear outside the ocelli, namely in the marginal ring structures, the subtentacular and the subumbrellar regions, and the velar and the tentacular surfaces. Such responses were induced only at light-off and never at light-on, and a few examples of pulses induced by shadows are shown in Figs. A-D.

In $A$, simultaneous recordings were made on the nerve ring (upper record taken at the position 2 on the right figure) and in the subtentacular region (lower record taken at the position 1). On the nerve ring, a pulse of a rather large amplitude is seen at first and then a very small pulse (marked by a dot) which is followed by a pulse of complicated waveform with larger amplitude (marked by a downward arrow) and then by two more large pulses of the first type. The amplitude of the large type of pulse ranged from 0.3 to $1.5 \mathrm{mV}$ and that of the second small type was mostly less than $0.5 \mathrm{mV}$. It must be noted that the pulse of the complicated waveform as marked by the downward arrow occurred in association with the velar contraction and also that such pulses were always preceded by the small type of pulse in the nerve ring. In the lower record, two pulses (shown by upward arrows) appear, which are composed of a quick and a slow phases. The pulse form of this type is magnified in F. It is not clear at present whether the two components are both conductive in nature or whether the quick one triggers the slow one in its passage. But from other types of experiments which will be reported elsewhere, this type of composite pulse appears to reflect events associated with a through conducting system and also to have a close relationship with the large type of pulse in the nerve ring. Such a coordinated appearance is clearly demonstrated between the two records in $A$.

In $B$, a typical off-response taken on the nerve ring is shown in the upper record together with a light-off signal and time marks of $100 \mathrm{msec}$ in the lower record. The response pattern is the same as that seen in the upper record in A, and the latency is about $0.9 \mathrm{sec}$. In general, the first electrical event on the nerve ring after the light-off could be either the large or the small type of pulse and in either case the latency was found to vary between 0.2 and $1.1 \mathrm{sec}$.

If a cut was made between the nerve ring and the ocelli as shown by a dashed line in the lower figure on the right, the off-response does not appear any more at the site No. 3 in C which corresponds to the site No. 2 in B. This clearly indicates that the responses recorded in $\mathbf{B}$ are triggered by signals originated in the region more distal to the cut line, most likely in the ocelli. At the site No. 4, slow negative pulses appear about $0.7 \mathrm{sec}$ after the light off (Record D). The pulse appeared in the lower trace in A (marked by the asterisk) is probably the same in nature. It would appear as if this type of pulse had played a role of information carrier from the ocelli to the nerve ring, but it is difficult to conclude in such a way because we have met so far no instance 
where such a slow negative pulse preceded the quick pulses which occurred in the nerve ring. It should be noted that the irresponsiveness of the nerve ring in $\mathrm{C}$ was not due to the result of operational damage, because pulses did appear spontaneously in the nerve ring (upper record in E) and in the region distal to the cut (lower record) which resemble, respectively, the large type of pulse in the nerve ring (upper record in A) and the slow negative pulse (marked by the asterisk in lower record in A) of intact preparations. In addition to those mentioned above, analyses of various other types of pulse as regards their origins, conduction velocities, mutual relationships, etc will be reported elsewhere. Though still preliminary, we think that the present study will provide a clue to study electrophysiologically the mechanism of shadow reactions in hydromedusae.

\section{REFERENCES}

Brown, H. M. \& OGden, T. E. 1968. The electrical response of the planarian ocellus. J. Gen. Physiol., $51: 237-260$.

Eakin, R. M. 1965. Evolution of photoreceptors. Cold Spring Harbor Symp. on Quant. Biol., 30: 363-370.

EAKIN, R. M. 1972. Structure of Invertebrate Photoreceptors. Chapt. 16 in "Handbook of Sensory Physiology, Vol. 7, Part 1, Photochemistry of Vision". Ed. H. J. A. Dartnall, Springer-Verlag, Berlin.

Hartune, H. K., Wagner, H. G. \& MacNichol, E. F. Jr. 1952. The peripheral origin of nervous activity in the visual system. Cold Spring Harbor Symp. on Quant. Biol., 17: 125-141.

Hisada, M. 1956. A study on the photoreceptor of a medusa, Spirocodon saltatrix. J. Fac. Sci. Hokkaido Univ., Series VI, 12: 529-533.

KIKUCHI, K. 1947. On the shadow reflex of Spirocodon saltatrix and their vertical distribution in the sea. Zool. Mag. Tokyo. 57: 144-146 (in Japanese).

Mackie, G. O. \& Passano, L. M. 1968. Epithelial conduction in hydromedusae. J. Gen. Physiol., 52: $600-621$.

Morin, J. G. \& COOKE, I. M. 1971. Behavioural physiology of the colonial hydroid Obelia. III. Characteristics of the bioluminescent system. J. Exp. Biol., 53: 723-735.

Passano, L. M. \& MCCullough, C. B. 1962. The light response and the rhythmic potentials of hydra. Proc. Nat. Acad. Sci., 48: 1376-1382.

Passano, L. M. \& MCCullough, C. B. 1964 . Co-ordinating systems and behaviour in hydra. I. Pacemaker systems of the periodic contractions. J. Exp. Biol., 41: 643-664.

WoollacotT, R. M. \& Zimmer, R. L. 1972. Fine structure of a potential photoreceptor organ in the larva of Bugula neritina (Bryozoa). Z. Zellforsch., 123: 458-469.

YAMASU, T. \& Yoshida, M. 1973. Electron microscopy on the photoreceptors of an anthomedusa and a scyphomedusa. Publ. Seto Mar. Biol. Lab., 20 (Proc. Second Internat. Symp. Cnidaria), 757-778.

\section{DISCUSSION}

MACKIE: I have only one question. Is it possible to grow Spirocodon in Canada?

YoshiDA: No. The best solution for you would be to come and study here in Japan. 
Braverman: In recent years evidence has begun to accumulate from a number of lines of investigation that variation in electrical potential may perform a guiding function for cell movements during morphogenesis. I should like to ask our neurophysiologically oriented colleagues whether in the course of their investigations they have noticed among the different pads of coelenterates endogenous potential differences which might function as morphological beacons.

Yoshida: We have not done such work as yet. But invaginating cells of the small ocelli of Aurelia might give us a possibility to tackle such a problem.

Passano (comment to question by Dr. Braverman): Dr. Kass-Simon and I attempted to correlate the reappearance of contraction burst pulse activity (in Hydra attenuata) following "decapitation" with the regeneration of the head. Regenerative events appear to preceed the reappearance of $C B$ pulses, so that the CB system does not appear to be causative to the regeneration polarity. 